\title{
Table tennis course teaching methods
}

\author{
Tie LI \\ Sports Dept. \\ Harbin P.E. Institute \\ Harbin, Heilongjiang, 150008 China
}

\begin{abstract}
This article uses the literature material law, the paper analyzes the physical quality, technical, tactical and psychological training in table tennis teaching characteristics, and puts forward problems that should be paid attention to in the process of the table tennis course teaching in college and universities and related practical application of teaching methods, to strengthen the college table tennis class teaching quality and enhance students' interest in learning table tennis.
\end{abstract}

Keywords- colleges and universities; Table tennis; Course; Teaching; methods

\section{INTRODUCTION}

table tennis is China's "national sport", as Brazil's football, basketball as well as in the United States. Chinese table tennis enthusiasts are many. In government agencies and large and medium-sized institutions, community residents, people playing table tennis sports can be seen everywhere. In our country from the "ping-pong diplomacy" to national fitness, table tennis involves many aspects of our lives. Table tennis' influence is not only the most widely in our country, and table tennis sport level of our country is in the lead in the world, we have a high level of teachers and coaches, they contributed to the development of table tennis. For colleges and universities, table tennis class's the main purpose is to get the table tennis on campus, to improve the influence of table tennis, this influence is mainly from improving the competitive level, the participation of students ability, etc, to make college students through sport exercise, improving their quality, we achieve the purpose of recreation, physical fitness, and professional table tennis is different, so in the course, scientific training and teaching methods have a great benefit to student's learning.

\section{THE REQUIREMENT OF PHYSICAL QUALITY TO THE TABLE TENNIS}

Physical quality is all sports technique and tactics, the cornerstone of the development of the psychological quality, common saying goes: "the body without strength, the heart without bottom," which is emphasizing physical quality for individual sports technology development level and tactical use of effect of the important influence. Physical quality mainly includes the strength, speed, stamina, agility and flexibility of five parts, from the perspective of the table tennis selection, table tennis' requirement of the basic physical quality accounted for eighty percent of the whole body quality comprehensive evaluation, and to the requirement of special quality it accounted for twenty percent, and the rate at which the individual relative strength and sensitivity of the demand is higher, while the stamina and flexibility requirements is low. Therefore, in the process of table tennis course teaching should be according to the characteristics of the student to provide guidance and help, targeted for the short and give priority to strength students, we should strengthen the flexibility of the usual training content, in view of short stature and those power relatively less we should strengthen the training of the lower extremities and swing arm strength. And the content of this part in the lesson plan strictly to ensure the physical quality of students can be improved in the actual teaching process.

\section{THE TABLE TENNIS TECHNICAL ANALYSIS}

Table tennis basic technology mainly includes the following aspects: (1) grip, basic position and basic posture; (2) basic footwork; (3) the serve, forehand, fire ball, forehand hair balls, spin and not turn sideways forehand hair on the left, back spin; (4) receiving technology; (5) the block ball: blocking the ball, fast or fast dial; 6. Strong: forehand attack, sideways attack, bat; Cruelly chop: fast and slowly rub; Today forehand and backhand combination technology: left push right attack. In table tennis teaching process, teachers should cultivate students with general physical quality at the same time, the development of special movement quality improve students' ability to participate in table tennis sports; Master table tennis major technology basic principle, take an active part in amateur table tennis match, improve the level of table tennis skills and tactics [1]. Table tennis technologies as a whole is relatively complex, and all stages some have different requirements, with table tennis serve as an example. Service is the only not controlled by the other party to the ball game, initiative, strong technology, within the scope of the rules, you can follow one's inclinations of the ball which will be sent to the other party. And other technology is different, your every board should be restricted by the other party, you want to sideways attack, at the same time you were afraid of the other party attacks you straight line, there is a restriction and the restriction, restrain and anti contain problems. Serve good technology, it can occupy initiative in the game, and 
effective service is connected each other, containing, or break down "grab" the initiative advantage, so in the game you has more than half chance to win [2].

\section{THE TABLE TENNIS TACTICS ANALYSIS}

Table tennis movement is mainly divided into the singles, doubles and mixed doubles three forms; each form of table tennis is different to the requirement of practitioners. Singles emphasize individual looking for aircraft, the ability to grasp the initiative, doubles and mixed doubles emphasizes the degree of coordination and tacit understanding between each other. So-called table tennis tactics is based on the method of performance and racket grip, making numerous individual tactical organic combinations to win in a game of tactical structure. Combine driving wheel and use patterns in the 1-35 shot hit the ball in the process, such as after receiving wheel tactics combination in the 2-4-6 when the shot hit the ball in the process [3]. As our country traditional correspondence is closer, mainly placing and the change of rhythm, rotation changes is complementary, attack and block the ball is the main fast-break game skill; Fox ring type style is given priority to with rotation changes, change speed and placement is complementary, forehand rushed combination, pull clasp combination is the core of the fox ring type play technology. So, only sportsmen are in the deep understanding of different tactics characteristic law to strengthen the predictability of the ball in the game, can they improve the accuracy of judgment, so as to formulate corresponding tactical action [4].

\section{TO IMPROVE THE QUALITY OF TABLE TENNIS TEACHING MEASURES}

\section{A. Improving table tennis students physical quality training plays an important role in improving table tennis skills level}

Table tennis is, in fact, the whole body movement. Although, in service, receive or vigorously smash or smoke hanging, the main part is upper limb of the wrist and arm, that is, they must use force; However, when moving or jumping, the trunk of the waist and legs must also participated in the activities of lower limb, they must be hard; While holding the racket, finger must also be strong. Thus, table tennis can make fully exercise the relevant parts of the body. Table tennis though is not quite as drastic as three big ball movements, in long time, but it also must have a certain resistance, namely lasting endurance ability or strength; especially in the competition, often use three out of five sets or four out of seven sets, that is certainly not without some sort of endurance. And endurance, the work is not the have to exercise gradually accumulated in the long run. Therefore, in order to enhance the students' endurance, we adopted the step-by-step training method, the strength of the practice and gradually increase the difficulty [5]. Therefore, in the table tennis teaching, aiming at the characteristics of students, to cultivate the students' bench press, speed, agility reaction ability is necessary; to improve the students' table tennis skill level has positive significance and function.

\section{B. Methods to promote table tennis technical level of the students}

Table tennis is very high to the requirement of technology, the technology is very complex, and from the grip, which serves to the forehand and backhand in accordance with the process of the application of technology, any technology and technology requires precise technique requirements. In the actual teaching process, we should let the student control the mirror from the simple act of learning, and then continuously correct technical movement, so that the students form a relatively accurate dynamic stereotype in mind. For example, the swinging Angle, speed and systemic coordinated, using the mirror control training and learning effect is better. For the forehand and backhand combining technology, it can be on the opposite side of the table tennis case, according to the position of the students standing on the table tennis in table tennis during the drawing this perfect lines, he is fixed with a rubber band, thus correcting students' mistakes technical action and helping the students improve the learning efficiency, improve the learning effect. In the actual teaching process, of course, there are many good teaching methods, this requires the teacher according to the professor in this paper summarizes the characteristics of students, and only in this way can we constantly improve the quality of the table tennis teaching, and improve the students' interest in learning and practicing.

\section{The role of psychological training methods in table tennis teaching}

Based on the characteristics of table tennis, psychological factors for table tennis final effect is obvious, table tennis can also constantly improve and perfect the students' psychological quality. Psychological training is consciously and purposefully develops students in training or competition; perfectly and reliably accomplish activities required by the psychological quality. Yog and liu Yang use cognitive training in table tennis basic technique teaching experiment research, the article mentioned that uses cognitive training conform to the normal physiological and psychological characteristics of college students, to mobilize students' learning enthusiasm, initiative and active classroom atmosphere has good effect. Of course, in some cases, it is also known as cognitive training image training or thinks of training, but no matter what kind of name it is, psychological training in table tennis play a role in the process of actual teaching and has been recognized by many scholars and experts. In fact, the psychological training method are many, from individual cognitive training, emotional control training, it will quality training and ability to resist setback training, all of these can be applied to the table tennis teaching process, the specific application methods should be based on students' personality characteristics, grasp the sports skill level after the comprehensive evaluation of the status of before it can be used. In addition, the psychological training is a long-term process, in the process of any sport, we just use one or several times, the effect is not obvious, therefore, we should follow the principle of psychological training. 


\section{CONCLUSIONS}

As the "national sport" of table tennis in the university campus it is relatively common, from the perspective of the table tennis teaching, table tennis to student's physical, technical, tactical and psychological requirement is very comprehensive and strict degree is higher, at the same time, table tennis is a fitness entertainment projects. Therefore in the table tennis teaching process, in order to cultivate students' interest in learning and practicing, we should do according to the different personality of students, and the characteristics of the sports level, target to adopt appropriate methods to student's physical quality, technical and tactical training, in addition, in the usual teaching process on the basis of follow the principle of psychological training and the method of psychological training should be introduced, that is to improve the students' learning enthusiasm and initiative and to improve the quality of table tennis course teaching.

\section{References}

[1] Liu Qingjian Zhong Yujing. The ordinary university table tennis course [J], the new system of Beijing sport university. 2011 (1), 92-95.

[2] Zhang Aili. Introduction to table tennis serve receiving technology and train [J], hubei sports science. 2000 (4), 20 to 22.

[3] Jian-jun tang Table tennis tactical system: tactical formation and use of technical action mode [J], journal of Beijing sport university. 2009 (4), 105-107.

[4] Qin Hua. The cultivation of table tennis tactical awareness[J], journal of weinan teachers college. 2004 (3), 63-65.

[5] Gong Zhongyong. Table tennis training and quality education [J], journal of bijie college. 2006 (6), 78-80. 